\title{
Solving rock mechanics issues through modelling: then, now, and in the future?
}

\author{
J Sjöberg Itasca Consultants $A B$, Sweden
}

\begin{abstract}
There is no dispute about the advances in numerical modelling for rock mechanics applications following its debut in engineering science some 50 years ago. Significant strides have been made since the days of punch cards and line printers, with modelling tools now being easy to use and capable of replicating many, but not all, aspects of rock behaviour. This paper explores some common rock mechanics problems in underground mining, and how these have been addressed through numerical modelling. The described issues include pillar design, ground support, caving prediction and ground subsidence, and mining-induced seismicity. Examples of how modelling technology has evolved over the years are given, while also pointing out current gaps and limitations in the technology. Finally, an outlook for the future is presented, including some of the challenges we are facing. An increased fundamental understanding of many rock mechanics issues is still required, but eventually one may envision a deep integration of rock mechanical modelling into mine planning and production, for a more sustainable future mining.
\end{abstract}

Keywords: numerical modelling, ground support, caving, mining seismicity, mine planning, design integration

\section{Introduction}

What is a 'model' and what is 'modelling'?. Looking these up in a dictionary, one finds the following definitions:

"A system of postulates, data, and inferences presented as a mathematical description of an entity or state of affairs. Also: a computer simulation based on such a system." (Merriam-Webster 2020)

"Scientific modeling, the generation of a physical, conceptual, or mathematical representation of a real phenomenon that is difficult to observe directly. Scientific models are used to explain and predict the behaviour of real objects or systems and are used in a variety of scientific disciplines, ranging from physics and chemistry to ecology and the Earth sciences. Although modeling is a central component of modern science, scientific models at best are approximations of the objects and systems that they represent-they are not exact replicas. Thus, scientists constantly are working to improve and refine models." (Encyclopaedia Britannica 2020)

The above definitions underline that models are always approximations, and not exact representations. Indeed, models must be simplifications, otherwise they would not be very useful. You can compare this to a map in a scale of 1:1 - it would be precise and detailed, but not very practical or useful for finding your way! This was perhaps even better stated in the seminal paper by Starfield \& Cundall (1988):

"After all, we build models because the real world is too complex for our understanding; it does not help if we build models that are also too complex. The art of modelling lies in determining what aspects of the geology that are essential for the model." (Starfield \& Cundall 1988)

You may replace 'aspects of geology' with 'geometry' and/or 'material behaviour', and this very much still holds true. As discussed by Starfield \& Cundall (1988), the upsurge in modelling th that time could be attributed to the ease of access to (then) powerful computers, and the increase in ability to include more 
details in the model. Now, more than 30 years later, this is even more so. We have models no one could even dream of before, both in size and degree of detail. We can simulate very complex material behaviour, and wow-what fancy plots and visualisations we can create! But have we progressed in solving basic rock mechanics issues? Have we advanced mining technology and design through modelling? In a slightly more recent paper, Jing \& Hudson (2002) stated:

\begin{abstract}
"Today's numerical modeling capability can handle very large-scale and complex equations systems, but the quantitative representations of the physics of fractured rocks remain generally questionable, although much progress has been made in this direction." (Jing \& Hudson 2002)
\end{abstract}

It appears that, at least in the early 2000s, there was still considerable uncertainty regarding some fundamental rock mechanical issues. Is this still the case today? For those interested in a comprehensive description of virtually all numerical modelling techniques, the paper by Jing (2003) is an excellent resource, but I will not dwell deeper on this. Instead, I will present some examples of how modelling technology has developed for different rock mechanics issues. This will be my take on the subject, with no illusions of this being complete, all-encompassing, or fully objective, but it will serve to illustrate some pertinent points. I will discuss current gaps and limitations, as well as future opportunities when it comes to rock mechanics modelling and its integration with mine planning and production.

\title{
$2 \quad$ Modelling case examples
}

\subsection{Modelling-assisted pillar design}

Pillars are one of the most important design elements in underground mining, being common in many methods-both left intentionally to support excavations as in room-and-pillar and cut-and-fill mining, but sometimes also left unintentionally, resulting in undesirable stress concentrations, such as in cave mining. In any case, knowledge of the stress conditions and the ability to design rock pillars is paramount to underground mining. An early example on the use of models to determine stress distribution is shown in Figure 1. This is not from a numerical model, but from a stress-optical model, using gelatine and fringe analysis to determine stress flow and stress concentrations. The results were more qualitative than quantitative. However, the importance of such models should not be underestimated, as they helped to understand the flow of stress and where stress concentrations, as well as destressed areas, develop.

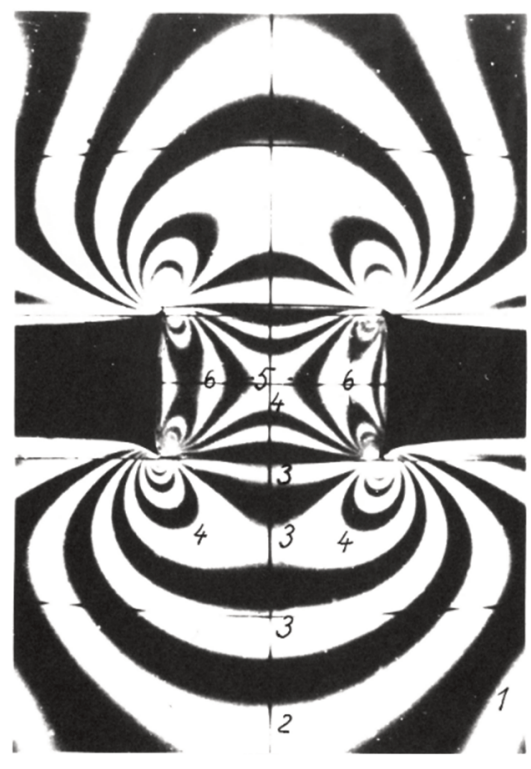

(a)

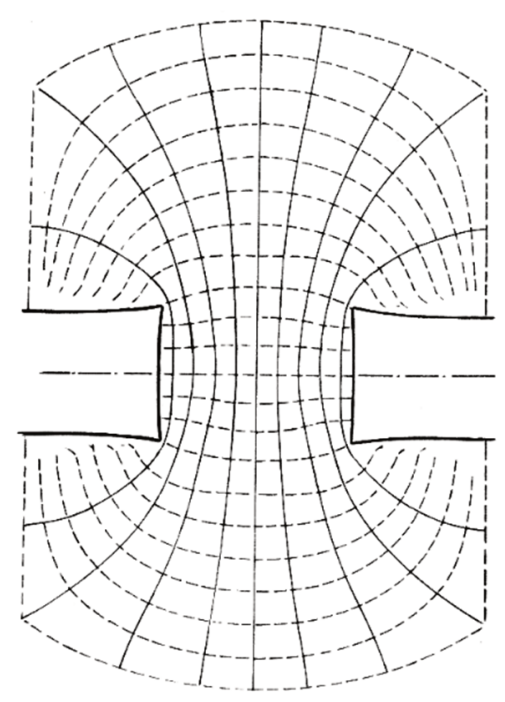

(b)

Figure 1 Results from stress-optical model experiment. (a) Stress contours; (b) Inferred major principal stress orientations (Kvapil 1965) 
Figure 2 shows an example where this technique was used to study alternative mining sequences for two subparallel orebodies in the Zinkgruvan Mine in south-central Sweden, and how the sequence affected pillar stresses. A more quantitative approach to stress analysis was the electric resistance analogue technique, often used for pillar stress analysis, e.g. Wilson \& More-O'Ferrall (1970). This can be seen as the forerunner of fully digital computer analysis, and it was not long until numerical modelling dominated the scene, replacing physical methods for stress analysis.

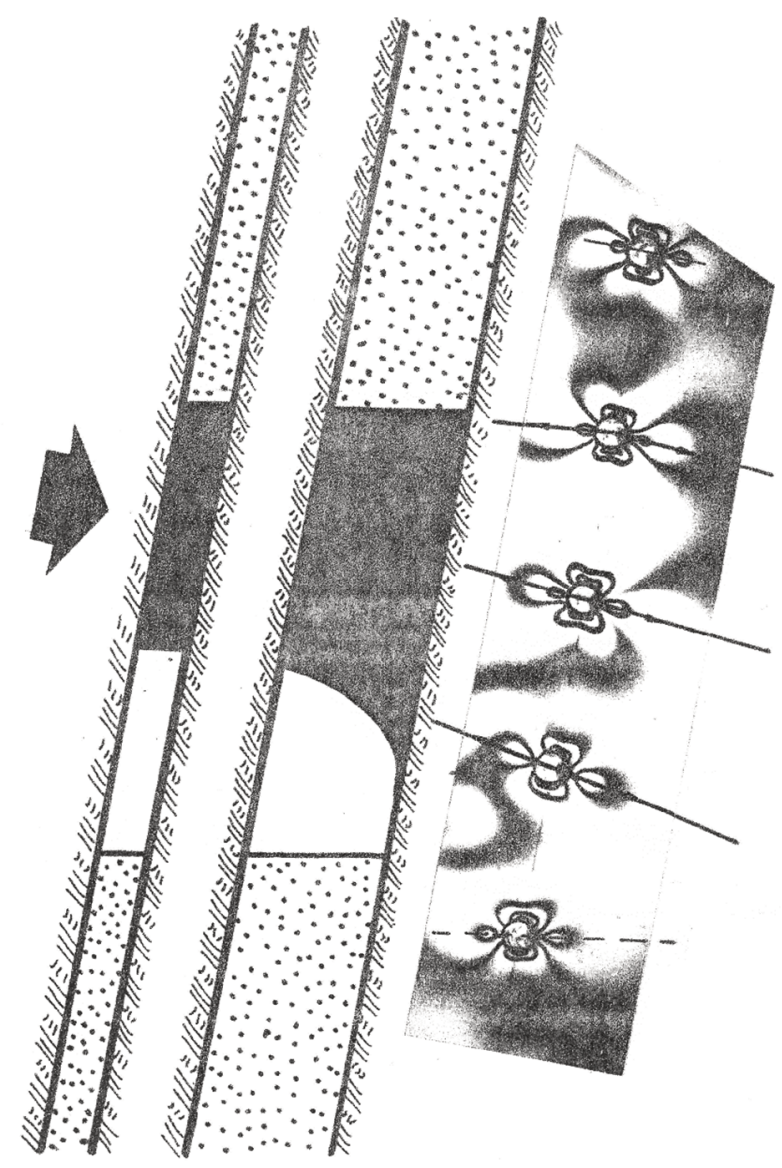

Figure 2 Results from a stress-optical model to study mining sequence of two parallel orebodies in the Zinkgruvan Mine, Sweden (Kvapil et al. 1967)

Using the same mine as an example, Figure 3 shows the results of 2D finite element modelling for two parallel orebodies. In this case, modelling was used to not only calculate stresses, but also to evaluate strains in the sill pillars. A linear-elastic material model was used, and calculated strains were compared to the extension strain criterion developed by Stacey (1981). Critical strain values were calibrated against observations of spalling and pillar instabilities, thus making this a predictive tool that could be practically used for mine planning. This was still strictly two-dimensional, but the emergence of the displacement discontinuity method and codes like NFOLD and MINSIM-D, led the way towards pseudo-3D analysis. These codes allowed modelling mining sequences within the orebody plane (for tabular, planar orebodies with constant thickness) and hence it was possible to study alternative sequencing for a range of mining methods in a meaningful way. An example is shown in Figure 4, in which pillar stresses were calculated for different mining sequences, but still employing a linear-elastic material model. Nevertheless, this represented a major step forward in using models to assist mining operations and design.

In many cases, one can gain a lot of understanding from 2D simplifications of what is really a 3D problem, as illustrated in the above examples. But there are also plenty of examples where a 2D simplification is not valid, and the next logical step was thus 3D models. While pillar design still often rests on empirical pillar formulas, amply summarised in Martin \& Maybee (2000), there are situations in which numerical modelling fills an important role, both with respect to complex geometry, as well as to material behaviour. 


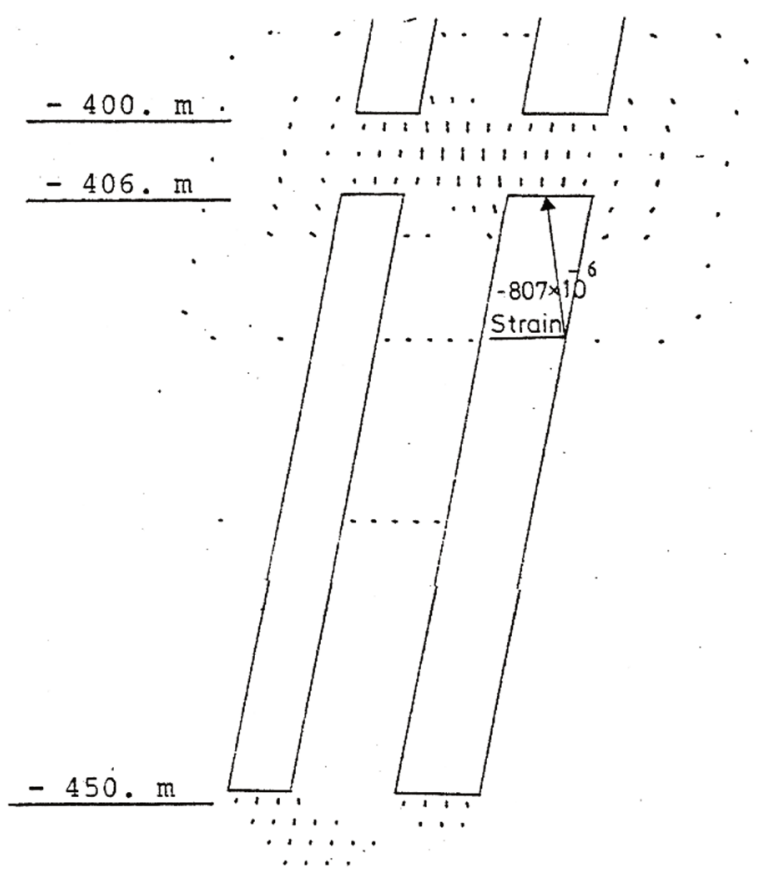

Figure 3 Results from a 2D finite element modelling showing calculated extension strains in sill pillars for two parallel orebodies in the Zinkgruvan Mine, Sweden (Borg et al. 1983)

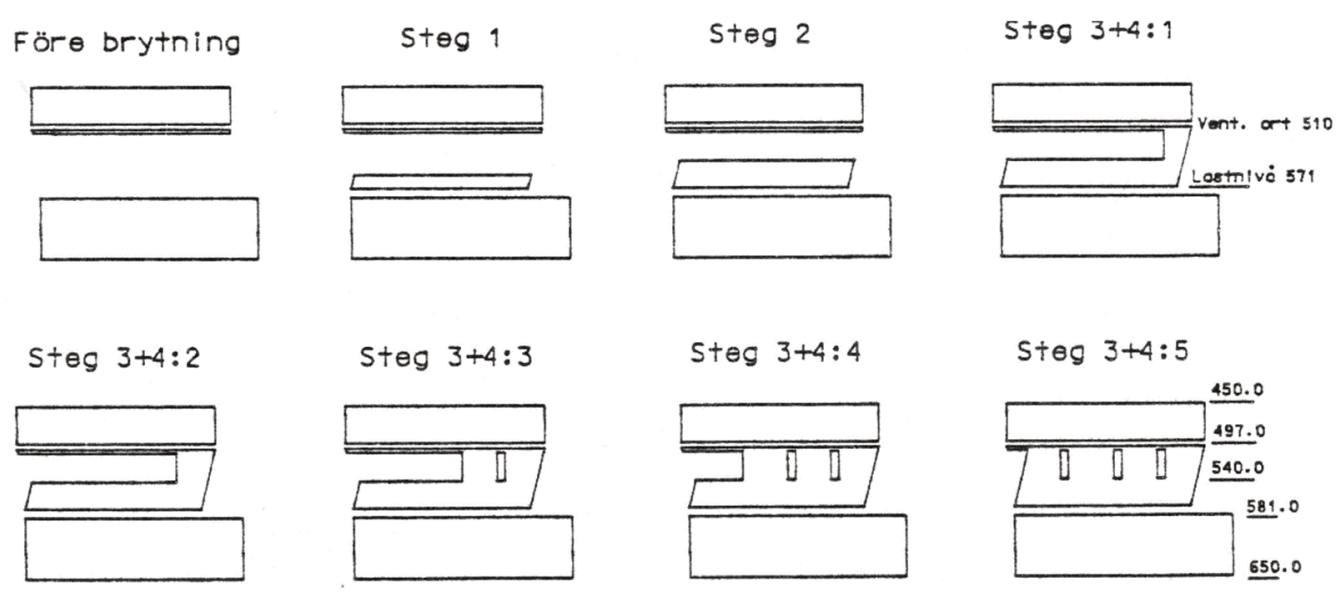

(a)

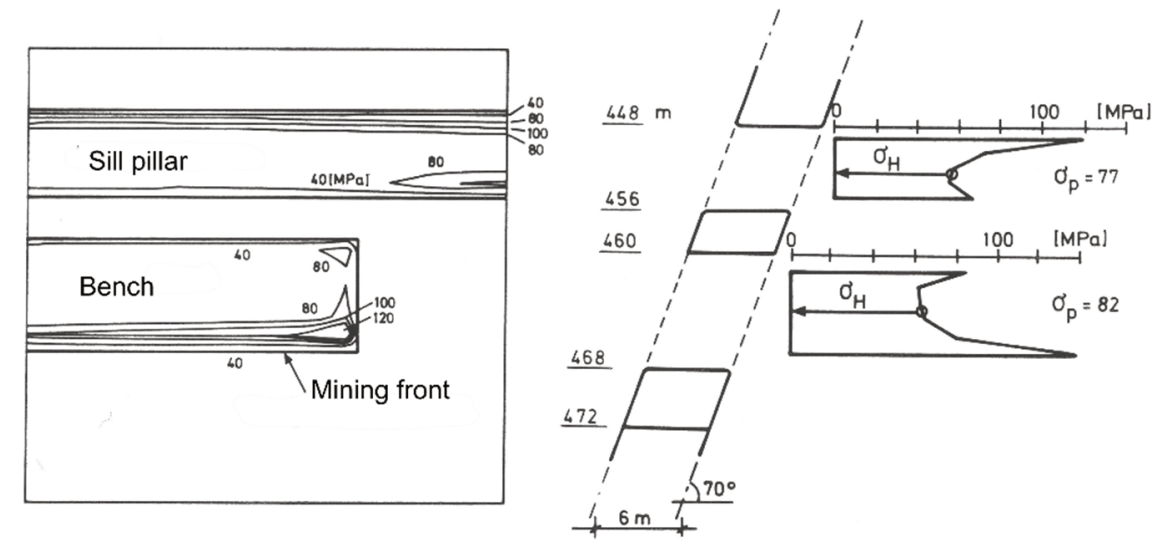

(b)

Figure 4 Application of 2.5D modelling for the Zinkgruvan Mine. (a) Simulated mining sequence for rill mining (Avoca Mining); (b) Calculated major principal stress in horizontal pillars (Sjöberg 1992) 
A clear illustration of when numerical modelling should be used instead of the typical empirical relationships for pillar design is presented by Garza-Cruz \& Pierce (2018), and Garza-Cruz et al. (2019a) in which the effect of acting shear stresses were quantified, with application to the Troy Mine. Shear stresses can develop in inclined seams or in mountainous areas, and the potential effects are not included in most pillar formulas. Garza-Cruz \& Pierce (2018) studied this using 3D discontinuum analysis and so-called bonded block modelling (BBM) in which the rock is simulated as bonded tetrahedral blocks that can break at their contacts, thus mimicking crack initiation and propagation in a rock mass. This type of modelling results in self-emergent damage.

The results confirmed that shear loading reduced the confinement in pillar core, and lead to the formation of en échelon fractures that can form a shear band, thus compromising the pillar stability (Figure 5). A pillar undergoing shear loading will have a lower load-bearing capacity than its counterpart loaded in pure compression. As a direct consequence, one should not design pillars that are expected to experience shear loading using relations developed with a pure compression loading assumption. Based on these results, design charts were developed to provide guidance on pillar geometry based on expected demand, and now using hydraulic radius as a better measure of pillar shape (than the commonly used width-to-height ratio). Supplementary 3D mine-wide modelling of planned pillar geometry then enabled concrete and detailed design recommendations to be made (Garca-Cruz et al. 2019a).

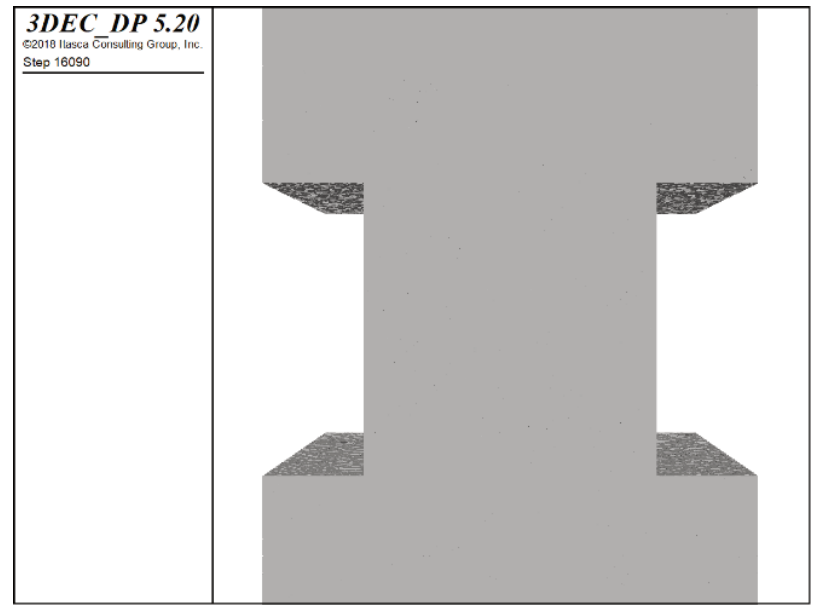

(a)

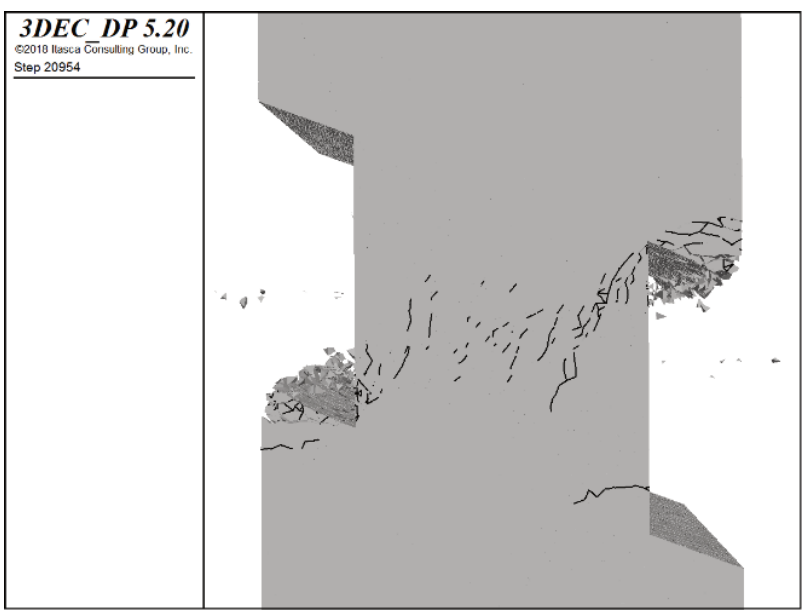

(b)

Figure 5 Analysis of pillar cracking. (a) Vertical pillar in horizontal seam with no shear loading; (b) Vertical pillar in inclined seam subjected to shear loading (Garza-Cruz \& Pierce 2018)

This is a good example of how modelling can be used first to understand mechanisms, and then to aid in mine planning and design. It also goes to show that we need to venture into more advanced material models to fully understand complex behaviour. This is not to say elastic modelling does not have its place (it certainly does) but we sometimes need simple models, and sometimes crave more complex models.

\subsection{Modelling ground support}

Ground support (or rock reinforcement) is a key aspect of safe and efficient underground mining. In the following, 'ground support' is defined as all types of support and/or reinforcement elements, including rockbolts, anchors, shotcrete, lining, and other surface support.

A lot of ground support design is experience-based and adjusted (or optimised) to local conditions. Analytical solutions work only for very simplified cases and empirical design charts may be unreliable when applied outside the limits of the data/experience on which they are based. The most commonly used empirical methods, often developed for civil engineering, do not typically work well for underground mines. Potvin \& Hadjigeorgiou (2016), and Potvin et al. (2019) pointed out serious shortcomings of, for example, the Norwegian Geotechnical Institute (NGI) Q-system approach, partially due to the database upon which it is 
based, in which there is a scarcity of mining case studies. Moreover, reinforcement methods such as mesh are commonly used in mining and not addressed in the NGI approach, whereas the opposite is true for shotcrete arches.

Empirical design approaches will, nevertheless, continue to be important-in particular at the early stages of a project, when data is limited. An approach using a mining database was proposed by Potvin \& Hadjigeorgiou (2016), and Potvin et al. (2019) for this purpose. However, when more data is available, and for more complex situations where a deeper understanding of the fundamental mechanics is required, numerical modelling provides an important function. Modelling is versatile, as almost all important factors can be accounted for in a model, but of course to various degrees of detail. More importantly, failure modes and mechanisms need not be assumed beforehand, but can be evaluated from emergent behaviour in a model.

For mining applications, the post-peak behaviour of both the rock and the support system is often important, e.g. in support design for burst-prone ground. This may be analysed using numerical modelling-while still complicated, but with more ease than using analytical or purely empirical methods.

Many codes now offer a range of structural (support) elements, with varying capabilities. There are still some limitations and differences in terms of the interaction between different structural elements, and how rockbolts and surface support are represented. Surface support, such as shotcrete, may be simulated as a structural element-essentially a beam, or a membrane/shell. This works well in the elastic range, but is more difficult if extensive yielding is expected in the surface support. Plastic moment and plastic hinges can be prescribed, but for extensive yielding a more versatile approach is to simulate shotcrete using elements (finite difference/finite element). This opens up to simulate more aspects of support behaviour, but it requires fine discretisation and thus longer calculation times, as well as more efforts when setting up a model.

A nice example of modelling surface support and bolts in order to understand governing factors is presented in Malmgren (2005). Two different rock masses, with a single discontinuity and with many discontinuities, were analysed (Figure 6). An example result is shown in Figure 7. This type of modelling helps to understand what type of failure can be expected in the ground support, and consequently guide on what to design for in different situations.

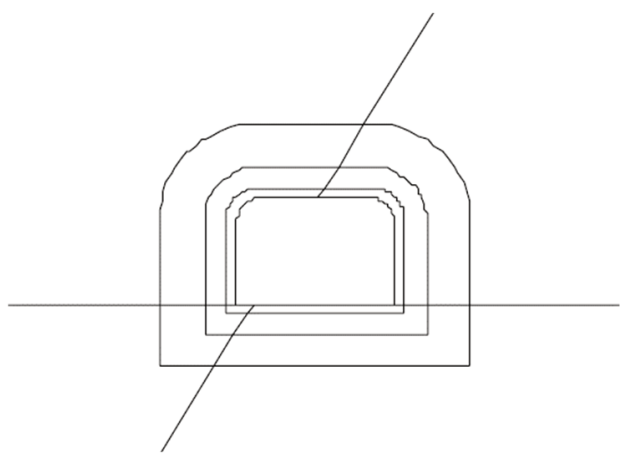

(a)

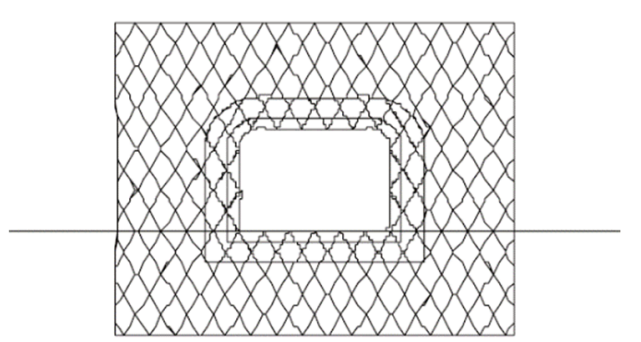

(b)

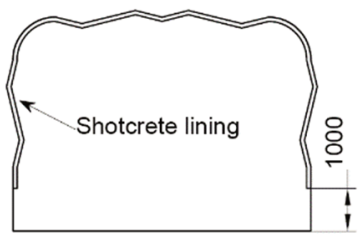

(c)

Figure 6 Analysed mining drift with shotcrete support. (a) Rock mass one discontinuity; (b) Jointed rock mass; (c) Drift geometry and shotcrete lining (Malmgren 2005) 


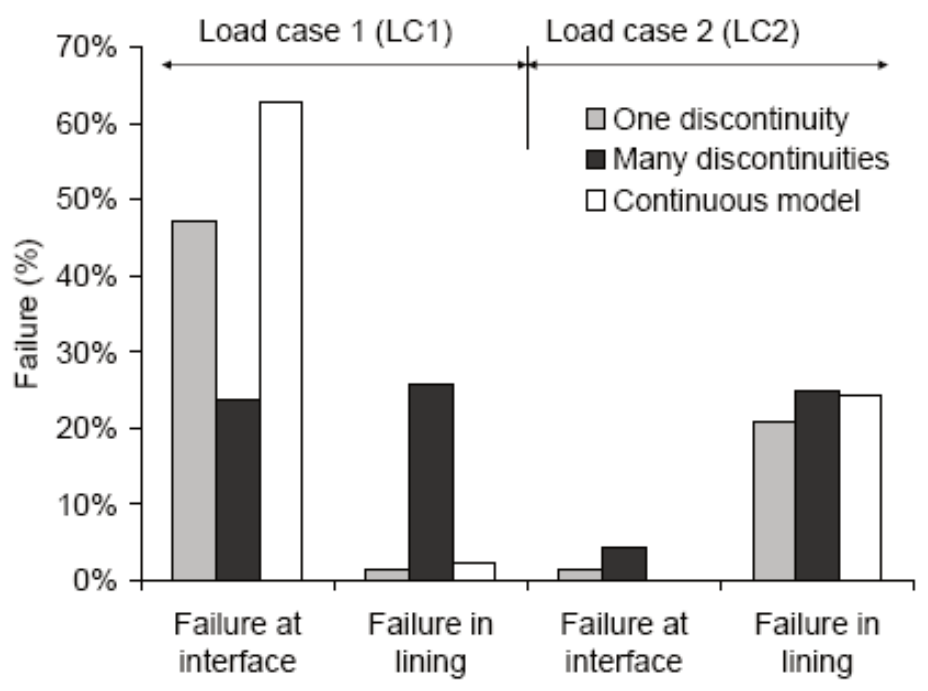

Figure 7 Results from analysed shotcrete support showing where failure occurred for simulated rock masses according to Figure 6 (Malmgren 2005)

Another example in which modelling illuminated support action was presented by Garca-Cruz et al. (2019b). BBM (see Section 2.1) was employed together with a newly developed hybrid bolt model. This bolt model can simulate resistance to fracture shear displacement more realistically, thus better replicating rockbolt action in a jointed rock mass. The hybrid bolt consists of two components: a cable with a specified tensile strength and stiffness that resists shear along its length (i.e. pull-out), and a dowel segment that resists lateral shear where the bolt crosses a rock joint. The dowel represents a set of complex mechanical effects, including bending of the steel bolt, crushing of the grout, crushing of the host rock, etc. The bolt properties are calibrated to reproduce the specified capacity and behaviour observed experimentally in pull-out and shear tests (Bouzeran et al. 2016). The three stages of load response (elastic, yield, and plastic stages) typically observed in laboratory tests are mimicked by the hybrid bolt model elements. In this particular case, ground support performance in access drifts at the Eleonore Mine was studied. The drifts are situated in competent rock and with undulating sub-horizontal and vertical jointing. The sub-horizontal joints are highly susceptible to shearing and opening under high horizontal stresses.

The results showed that the falls of ground experienced at the mine are due to the rebar bolts in the back being heavily strained locally through sub-horizontal joint shearing, causing them to rupture (Figure 8). A bolt with higher shearing capacity is thus required to support the on-ore drifts. Both D-bolts and larger-diameter rebars were analysed as alternatives with the model, and both showed superior deformation compatibility, which also agreed with experience in the mine (Figure 9). A design with $4.5 \mathrm{~m}$ long Super Swellex and $10 \mathrm{~m}$ long cable bolts as secondary support, in addition to the primary support with $2.4 \mathrm{~m}$ long rebars, was also analysed. It was found rebars ruptured, while most of the Super Swellex and cable bolts survived. A noteworthy result is that only the lower half of the $10 \mathrm{~m}$ cables were activated, implying that shorter cables could provide the same level of support. However, while this design is able to keep part of the back in place, most of the ground support elements are compromised and this support design is not adequate, especially for deeper levels. This case study is a good illustration of how numerical models can be used to better understand the mechanisms and interactions between the rock and the ground, by allowing for realistic fracturing and bulking of the rock mass along with structural elements that model ground support action more realistically. Ultimately, this aids in optimising support design under complex conditions. 


\begin{tabular}{c}
$3 D E C D P$ 5.20 \\
O2018 Itasca Consulting Group, Inc. \\
Step 229913 \\
4/25/2018 5:52:07 PM \\
\hline Bars: Cable axial force (Tension-) \\
Axial rupture \\
Axial yield (compression) \\
Axial yield (tension) \\
Yield in past \\
$0.0000 \mathrm{E}+00$ \\
$-5.0000 \mathrm{E}+04$ \\
$-1.0000 \mathrm{E}+05$ \\
$-1.5000 \mathrm{E}+05$ \\
Cable displacement magnitude \\
$5.0000 \mathrm{E}-02$ \\
$4.0000 \mathrm{E}-02$ \\
$3.0000 \mathrm{E}-02$ \\
$2.0000 \mathrm{E}-02$ \\
$1.0000 \mathrm{E}-02$ \\
$0.0000 \mathrm{E}+00$ \\
Z-displacement \\
Plane: active on \\
$0.0000 \mathrm{E}+00$ \\
$-5.0000 \mathrm{E}-03$ \\
$-1.0000 \mathrm{E}-02$ \\
$-1.5000 \mathrm{E}-02$ \\
$-2.0000 \mathrm{E}-02$ \\
$-2.5000 \mathrm{E}-02$ \\
$-3.0000 \mathrm{E}-02$ \\
$-3.5000 \mathrm{E}-02$ \\
$-4.0000 \mathrm{E}-02$ \\
$-4.5000 \mathrm{E}-02$ \\
$-5.0000 \mathrm{E}-02$ \\
\end{tabular}

\section{End of stope excavation $($ Depth $=440 \mathrm{~m})$}

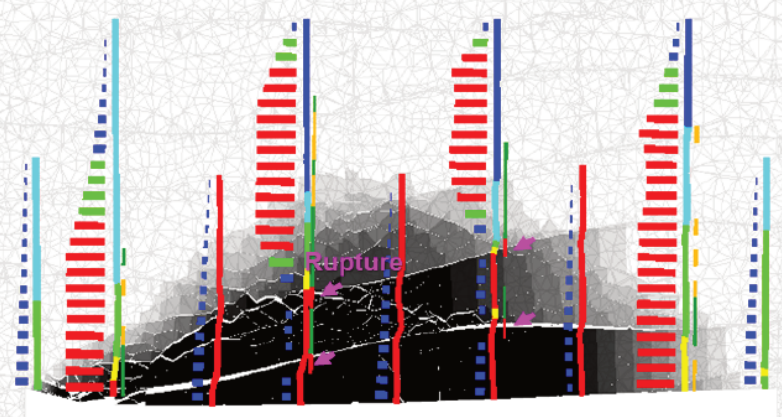

Rebars ruptured, split sets are slipping out of the hole

$$
\text { Unstable - back in state of collapse }
$$

Figure 8 Simulated ground support response at the Eleonore Mine with rebars being subjected to high shear loading and rupturing, and split set bolts slipping out of the holes (Garza-Cruz et al. 2019b)

\begin{tabular}{c} 
3DEC D $\boldsymbol{D}$.20 \\
O2018 Itasca Consulting Group, Inc. \\
Step 129913 \\
4/2/2018 7:17:18 PM \\
\hline Bars: Cable axial force (Tension -) \\
Axial rupture \\
Axial yield (compression) \\
Axial yield (tension) \\
Yield in past \\
$0.0000 \mathrm{E}+00$ \\
$-5.0000 \mathrm{E}+04$ \\
$-1.0000 \mathrm{E}+05$ \\
$-1.5000 \mathrm{E}+05$ \\
$-1.6000 \mathrm{E}+05$ \\
Cable displacement magnitude \\
$5.0000 \mathrm{E}-02$ \\
$4.0000 \mathrm{E}-02$ \\
$3.0000 \mathrm{E}-02$ \\
$2.0000 \mathrm{E}-02$ \\
$1.0000 \mathrm{E}-02$ \\
$0.0000 \mathrm{E}+00$ \\
Z-displacement \\
Plane: active on \\
$0.0000 \mathrm{E}+00$ \\
$-5.0000 \mathrm{E}-03$ \\
$-1.0000 \mathrm{E}-02$ \\
$-1.5000 \mathrm{E}-02$ \\
$-2.0000 \mathrm{E}-02$ \\
$-2.5000 \mathrm{E}-02$ \\
$-3.0000 \mathrm{E}-02$ \\
$-3.5000 \mathrm{E}-02$ \\
$-4.0000 \mathrm{E}-02$ \\
$-4.5000 \mathrm{E}-02$ \\
$-5.0000 \mathrm{E}-02$ \\
\end{tabular}

\section{End of stope excavation $($ Depth $=440 \mathrm{~m})$}

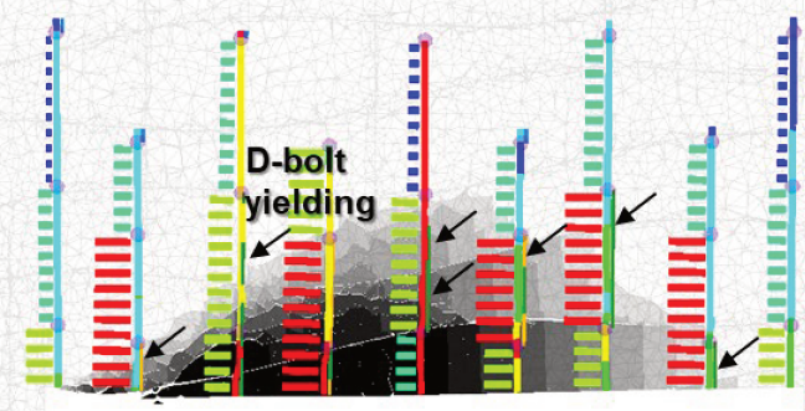

Stable, $\sim 50 \%$ of max shear strain reached

Figure 9 Simulated ground support response at the Eleonore Mine with D-bolts successfully carrying induced shear loads (Garza-Cruz et al. 2019b)

The cases presented above are examples of explicit modelling of ground support elements, to simulate the interaction between the reinforcement/surface support and the rock mass, as it deforms. Other examples of explicit discontinuum modelling can be found in Jalalifar \& Aziz (2012) and Karampinos et al. (2016). However, 
there are still several aspects of explicit modelling of ground support that are missing or need improvement. It is, for example, still cumbersome to model failure of shotcrete in models with structural elements. Modelling of mesh also presents some challenges, as well as simulation of failing ground subjected to dynamic loading. The interaction between different support elements may also need improvements in certain aspects. It is also clear that any opportunities to calibrate models-with and without ground support-should be used (more on this below in my vision for the future).

One should also consider using modelling tools without explicitly including support elements. Such a non-explicit approach focuses on assessing a zone of failed ground around excavations using calibrated failure criteria, and uses a limit equilibrium calculation to support the dead weight of the failed ground (Potvin et al. 2019). In many cases, explicit support modelling may not be a tool for routine engineering analyses at a mine site. A non-explicit approach in which, e.g., the effect of the ground support is accounted for by an equivalent support pressure, may be useful. Potvin et al. (2019) also described a probabilistic approach combining limit equilibrium DFN analysis and non-explicit numerical modelling of ground support. It should be borne in mind, however, that such approaches must rest on a sound and fundamental understanding of the mechanics of the problem. Otherwise, one may end up designing for a non-critical problem possibly resulting in a non-conservative design.

\subsection{Advances in modelling of caving}

Cave mining methods, such as block caving, panel caving, sublevel caving, etc., are becoming increasingly popular and applied at more varying ground conditions and depths than ever before. It is only natural that numerical modelling of different aspects of caving has developed and matured over the years, with a more rapid development pace during the last decade or so. In the early days, physical modelling was the method of choice to study gravity flow and ground subsidence associated with caving methods. An example is shown in Figure 10, using basal friction models to study hangingwall caving mechanisms due to sublevel cave mining in the Kiirunavaara Mine in northern Sweden, owned and operated by Luossavaara-Kiirunavaara Aktiebolag (LKAB).

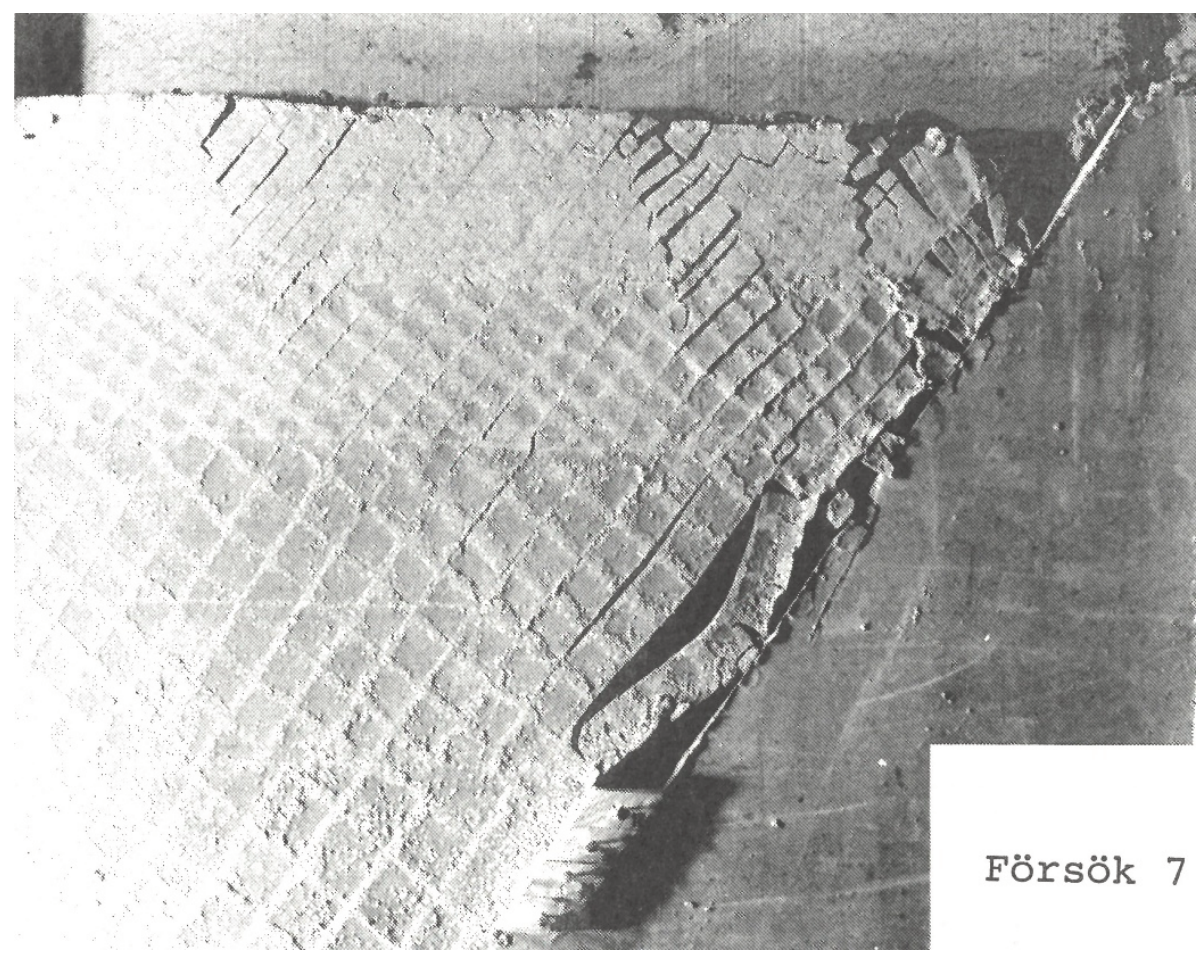

Figure 10 Results from basal friction physical models of sublevel caving at the Kiirunavaara Mine (Stephansson et al. 1978) 
Similar to the stress-optical models described in Section 2.1, these types of models, although not numerical, offered insight and understanding of some of the basic principles governing caving. Obviously, they required more time to develop and parametric studies were, for the most part, cost- and time-exclusive.

Numerous additional analytical and modelling work has been conducted for the Kiirunavaara Mine. With the municipality of Kiruna located in close proximity to the mine, and primarily on the hangingwall side, mining-induced caving and deformation have a direct impact on the possibility to retain the residential buildings and infrastructure of the city. A process of 'urban transformation' is now in place in which the city of Kiruna is progressively relocated to a new area, undisturbed by mining activities. Thus, it is important to have some means of predicting the overall surface effects. Following the physical model experiments, several limit equilibrium analyses, assuming rigid body movement, were developed; e.g. Herdocia (1991), Hustrulid (1991), and Lupo (1996). These were calibrated against previous observations and then used for prediction purposes. However, none of these claimed to model the physics of the problem at hand, and it became apparent that their predictive capability for future mining, at larger depth and with possibly different ground conditions, was limited.

Singh et al. (1993) presented some 2D numerical modelling of hangingwall failure, but in a purely continuum model and with low resolution. Villegas (2008) and Villegas \& Nordlund (2008) presented a methodology based on two-dimensional finite element numerical modelling in which the cave development was simulated in a novel way. In this work, the rock mass was modelled as a continuum without any joints or structures included but with the caving process represented with an algorithm in which the properties of the hangingwall were changed successively to simulate the propagation of caving toward the surface. The analyses were calibrated against measurements and observations and allowed the failure limit to be predicted for future mining. This represented a major step forward and was soon followed by more advanced methods to simulate the caving process.

One particular example is the caving algorithm, which was developed as part of the International Caving Study (ICS I and II) and Mass Mining Technology (MMT) projects, and used successfully at a number of existing and planned caving projects; see for example Sainsbury et al. (2010, 2011a, 2011b), Álvarez et al. (2014) and Cancino et al. (2020). The caving algorithm attempts to predict the limits of the five geomechanical zones associated with caving in the conceptual model by Duplancic \& Brady (1999): (i) elastic zone, (ii) seismogenic zone, (iii) yielded zone, (iv) air gap, and (v) mobilised zone. The algorithm allows drawing of material from the model, while maintaining mass balance rigorously, and allowing caving, yielding, and deformation zones to develop in the surrounding rock. The constitutive rock mass response required to represent caving was developed through the use of the strain softening so-called 'CaveHoek' constitutive model. This model allows for representation of modulus softening, density adjustment, dilation, dilation shutoff, scaling of properties to zone size, cohesion weakening, tension weakening and frictional strengthening (Pierce 2013).

The caving algorithm and the CaveHoek constitutive model were first applied to the Kiirunavaara Mine by Sainsbury \& Stöckel (2012). In this work, only historical mining was simulated. The methodology was re-applied, with refined calibration against cratering observations and then model validation using deformations measurement data, followed by simulation of future mining (Sjöberg et al. 2017). The modelling results showed that the extent of the zone of mining-induced deformations on the ground surface increased significantly with future mining at depth (Figure 11), continuing in more-or-less the same fashion as historically, when mining continues for another 300-400 m towards depth. Thus, there appears to be no, or at least very little, effect from increased confinement and bulking with deeper mining, something which had been debated at length previously. Thus, these models provided an improved basis for long-term planning of the urban transformation, which has a large financial impact for the mining company (LKAB). 


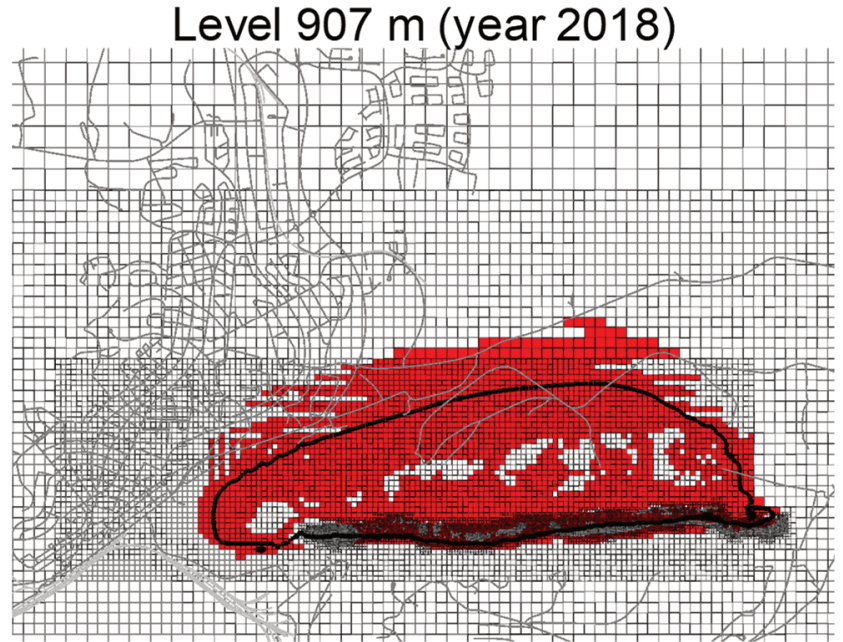

(a)

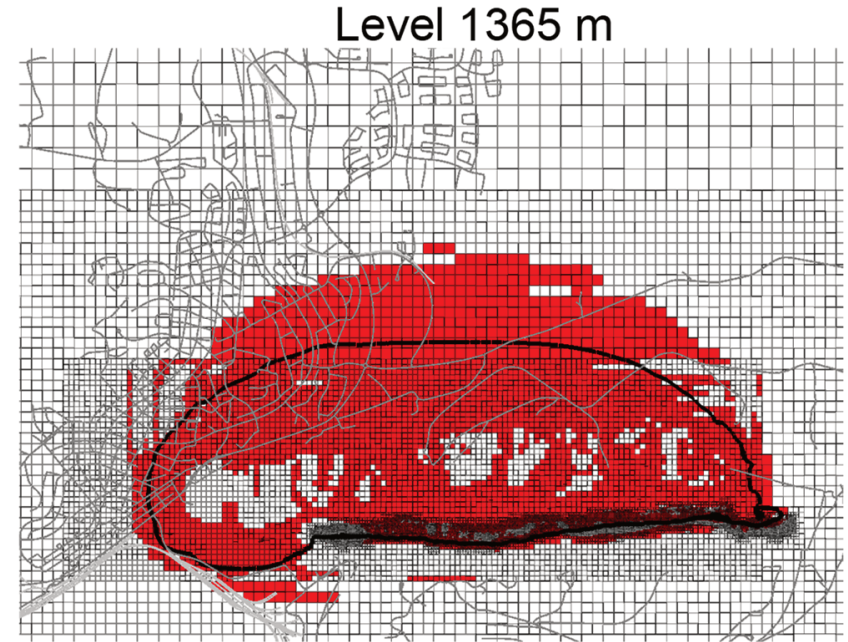

(b)

Figure 11 Area on the ground surface for which the environmental deformation criterion for the Kiirunavaara Mine was exceeded in the model (red colour) for mining to (a) Level $907 \mathrm{~m}$; and (b) Level $1365 \mathrm{~m}$. The indicated limit of surface cratering in the model is marked with a thick black line (Sjöberg et al. 2017)

A further development of the caving algorithm was presented by Hebert \& Sharrock (2018), utilising a bi-directional coupling method between the continuum code FLAC3D and the cellular automata code CAVESIM. It remains difficult to simulate granular flow in mine-scale flow problems using discontinuum analysis, mainly due to computational limitations. Cellular automata methods are, on the other hand, well-suited to extremely large and complex problems in discrete systems, and have gained wide acceptance in the fields of discrete mechanics. CAVESIM simulates gravity flow of caved rock in block and sublevel caves, with accurate representation and control of material bulking, as well as modelling material flow against static faces and around or against disturbing features such as cave sidewalls, overhangs, hang-ups and pendants (Hebert \& Sharrock 2018). A similar approach with an integrated coupled solution between a cellular automaton extraction and flow simulation and a finite element geomechanics simulation was described by Arndt et al. (2018), using PCBC for the flow simulation and Abaqus for the finite element analysis. This automated process was claimed to both accelerate the cave modelling processes and reduce manual processing time, as well as to allow use of the full simulation cycle in case studies and sensitivity analysis.

This technique has recently been applied to the Kiirunavaara Mine case together with a further development of the CaveHoek material model, called the Itasca Model for Advanced Strain Softening (IMASS) (Svartsjaern et al. 2020). In this work, particular focus was also placed on investigating the potential effects from large-scale structures on the hangingwall caving behaviour and ground surface deformation pattern. The model comprised a number of large-scale ductile deformation zones, an orebody, and separate host rock on the footwall and hangingwall side (Figure 12).

It was clearly shown that the large-scale deformation zones could significantly affect the ground surface deformation and the fulfilment of the environmental criteria for the site. The detrimental effects on surface infrastructure at the structure locations were indicated to appear in the field mainly between 2018 and 2028, at increasing distance from the mine, in the model timescale. There is likely to be interaction between the different structures; however, structures oriented parallel to the orebody strike will be affected by the mining advance in the same way regardless of the simultaneous existence of sub-perpendicular structures (Figure 13). The model also showed that the emergent yielding pattern indicates that caving of the hangingwall is not a continuous process, which can be directly related to the production schedule. From the model results there seems to be more-or-less active periods of caving and emergence and failure of elastic rock bridges. 


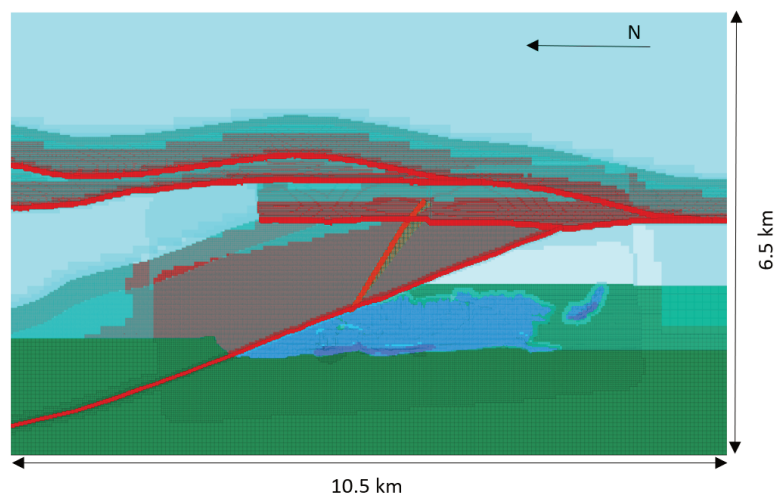

(a)

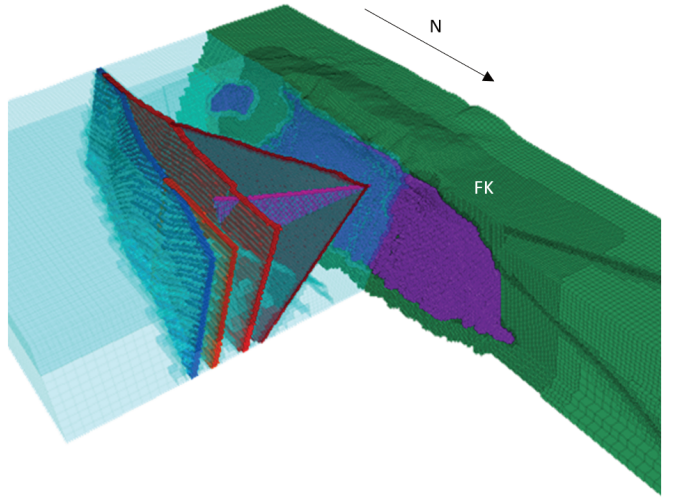

(b)

Figure 12 Model as seen from (a) Above; and (b) In isometric view with half of the hangingwall hidden for clarity, with footwall in green, hangingwall in semi-transparent teal, ore in purple and large-scale deformation zones in red and blue (Svartsjaern et al. 2020)

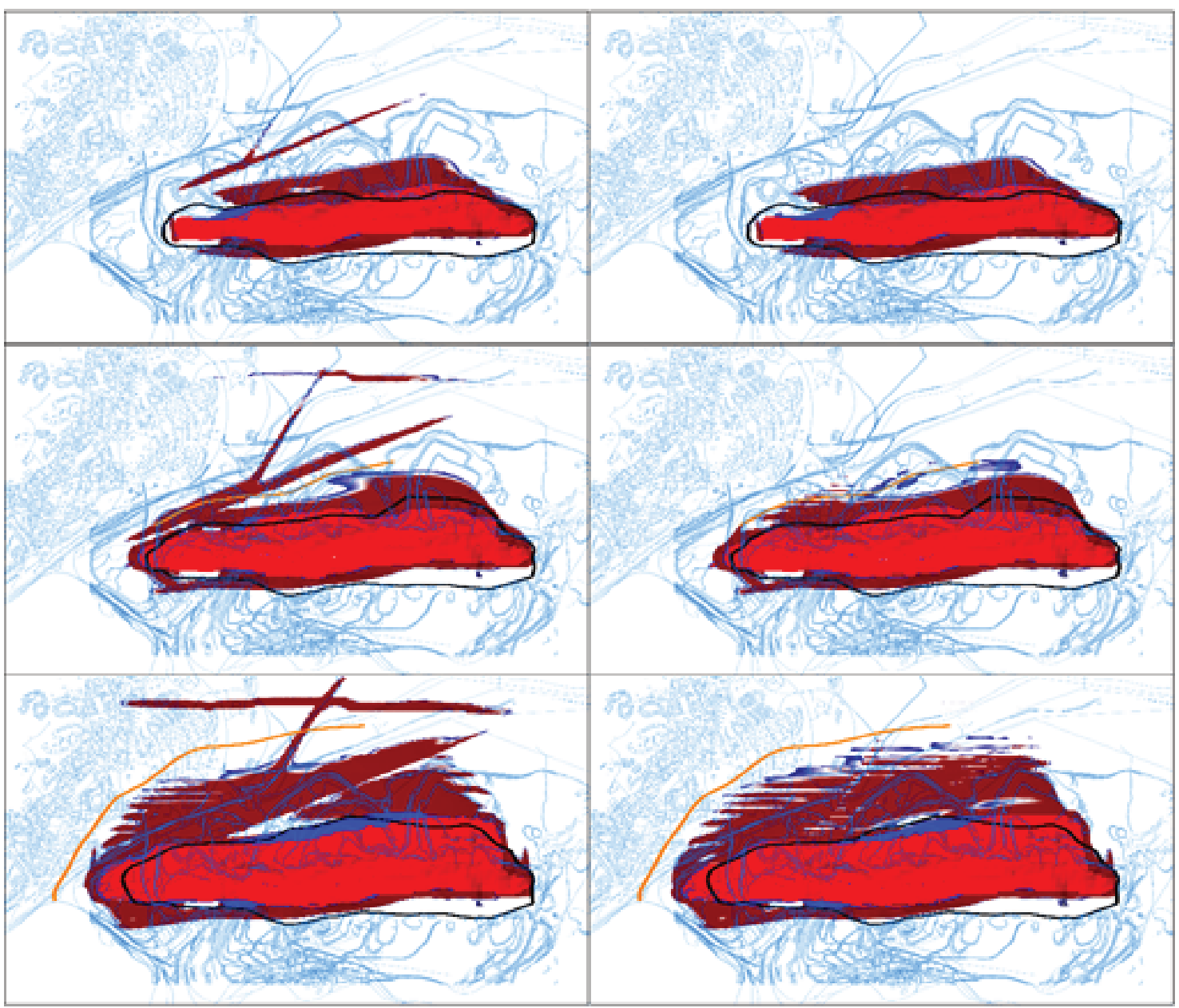

Figure 13 Progressive fulfillment of the environmental criterion in model with large-scale deformation zones (left column) and model without structures (right column) for mining corresponding to years 1996, 2008, and 2028. Red areas correspond to cave crater in the model, brown areas correspond to the environmental criterion strain limit for the mine, yellow lines show the predicted environmental criterion limit location and black lines show the observed cave crater (Svartsjaern et al. 2020) 
The current prognosis methodology at the site is based on empirically derived limit angles for caving and surface deformation limits. These have proven to work satisfactorily so far, and they are consistently reasonable for future mining, if not considering the local effects at the large-scale structures. However, if the effects of the structures are completely disregarded, the limit angles show a tendency to become non-conservative (underestimate ground surface effects) after mining to year 2028.

This type of modelling is regarded as extremely valuable for the mine, and for several reasons. First, it provides a deeper understanding of the possible mechanics of mining-induced caving and deformation, and how this may affect the ground surface at the site. In this context, such explicit modelling aids in verifying or discarding empirical prediction models. While such models remain important due to their ease-of-use for routine prognosis, their validity needs to be constantly assessed. Second, the coupled material flow-mechanical modelling aids in deciding what additional investigations and remedial measures should be undertaken. The models showed, for example, that significant focus should be placed on better understanding the location and properties of large-scale deformation zones, as well as monitoring displacements in and near such zones. Currently, there are few, if any, displacement data from structures located far from the mine. The modelling showed that some of these may already be affected by the mining process, but this cannot be verified. Additional efforts should thus be directed towards displacement measurements, using both surface and sub-surface (borehole) monitoring.

The advances made in recent years regarding modelling of caving is significant, and now allow realistic representation of both material flow, and stresses and deformations in the rock mass. These types of models can provide direct input to the mine planning process, but perhaps their largest benefit is that of increased understanding of the factors governing caving, material flow, and deformation effects. Even though assumptions regarding, e.g. the extent and characteristics of large-scale structures or other less-well defined features may be necessary, the model results are still valuable for increasing our understanding and help to define required investigations.

\subsection{Modelling mining-induced seismicity}

With deeper mining and increased stresses, and maybe also a desired increase in extraction ratio, mining-induced seismicity is becoming one of the most important rock mechanics concerns associated with mining. It is likely that a majority of mines must deal with seismicity in some way, to allow for safe and reliable mining under these conditions. We know that seismicity and associated rock damage occurred in the Kolar Gold Field in India more than 100 years ago, and a few years later problems appeared in the South African reef mines. We also know well what the causes of seismicity are, and seismic networks with geophones and/or accelerometers arranged in a network array in a mine have become the standard tool for monitoring seismicity in mining. However, microseismic monitoring is reactive in the sense that it only provides information on what has happened, and cannot generally be used for predicting future seismicity, other than in crude terms, e.g. maximum anticipated magnitude (Gutenberg-Richter relation) for a certain area. Our capability to predict when and where seismic events occur is still limited since one cannot, in general, predict future seismicity based solely on previously recorded seismicity. Moreover, in mining applications one may also need to distinguish between those events that cause damage (i.e. rockbursts) and those that do not. The quote from Salamon (1993) is fitting in this respect:

"No mining geometry or layout appears to exist which unfailingly leads to a seismic occurrence. At best, the likelihood of a seismic event is greater in one situation than in another. Thus, seismicity is a statistically predictable rather than deterministically foreseeable phenomenon." (Salamon 1993)

Numerical modelling has materialised as a tool to help understand and predict mining-induced seismicity. Using numerical modelling, future mining scenarios can be simulated and their possible consequences in terms of potential for rock failure and/or seismicity quantified. As such, modelling provides a path for improved predictive capability, which, in turn, serves as important input to the mine planning process. 
One can distinguish between two different approaches to modelling with respect to seismicity: static stress modelling and dynamic stress modelling. Calculation of static stresses is relatively straightforward, as has been described for some of the other cases in this paper. The representation of the rock mass behaviour, both pre- and post-failure, is increasingly important for seismicity applications and the underlying material models may need additional attention. The calculation of dynamic stresses and associated displacements is a more difficult problem. There are many commercially existing computer codes capable of dynamic analysis, but there are few examples of mine-scale applications. This is mostly related to the need for having a very fine discretisation of the numerical model to accurately capture the stress wave transmission through a material, which becomes computationally prohibitive for the mine-scale. There have been some recent advances with coupling of methods to model seismic waves and conducting stress analysis (see e.g. Wang \& Cai 2017, and Figure 14).
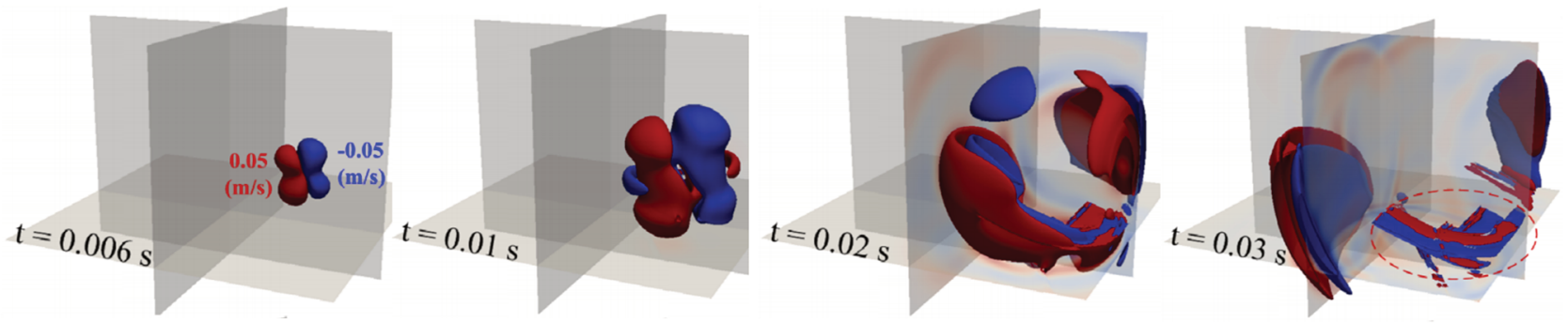

Figure 14 Isosurfaces of the vertical velocity component $(\mathrm{Vz}, \mathrm{m} / \mathrm{s})$ at five propagation times for a point source model showing effects of haulage tunnel and mined areas on wave propagation

However, static stress analysis is currently the only practical alternative for mine-scale rock mechanics modelling. For these types of models, an evaluation criterion is required to relate the calculation results to seismic parameters and estimation of the potential for seismic events. For strainburst events, several attempts at predicting the occurrence have been made based on evaluating overstressed volumes of the rock mass (e.g. Andrieux 2010). Another example of this type of work, in this case using 3D modelling in Abaqus, was presented by Beck et al. (2009) and, more recently, Vatcher et al. (2019) using FLAC3D.

Analysis of fault slip events has initially built on the excess shear stress (ESS) concept (Ryder 1987, 1988). Salamon (1993) and later Board (1996) developed a methodology for static simulation of seismicity using the ESS concept. In this methodology, a fracture pattern was simulated in the rock mass and the shear and normal stresses at the location of each fracture determined, and the corresponding ESS calculated. Only continuum modelling was used, thus not simulating shear displacements explicitly. This type of analysis does not account for the kinematics of shear slip and possible interaction between discontinuities.

Examples of discontinuum modelling with explicit representation of shear slip are found in Jarufe Troncoso et al. (2012), and Beck et al. (2012). Often, the seismic moment is often used to compare results from a numerical model with actual observed behaviour (Figure 15).

More recent examples of this concept are found in Malovichko (2017), attempting also to quantify seismic hazard by calculating ground motions. The ground motion hazard was quantified through calculated probability that strong ground motion from a seismic event will exceed a given threshold in a given place within a given period of time in future (Figure 16).

A true discontinuum model, in which all aspects of kinematics were addressed, was used in Sjöberg et al. (2012). The seismic moments were determined based on calculated shear deformation along geological structures. The obtained values were compared with data from seismic monitoring, and a set of future mining scenarios were simulated, and the resulting accumulated seismic moments (from all geological structures) calculated. This provided a quantitative comparison of the seismic potential for future mining. 


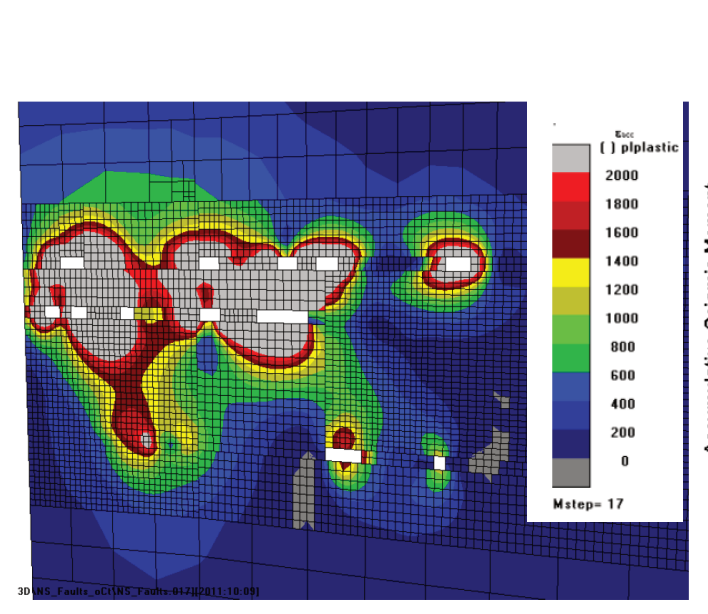

(a)

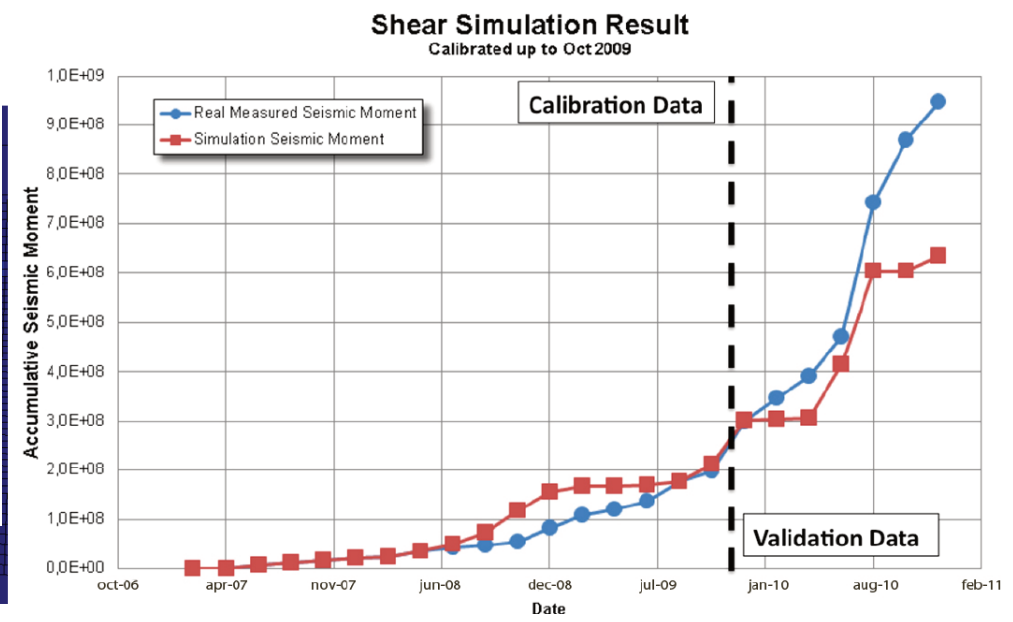

(b)

Figure 15 (a) Calculated plastic strain on displacement discontinuity plane; (b) Comparison between the measured seismic moment on shear zones (blue line) and the modelled calibrated result (red line) (Jarufe et al. 2012)

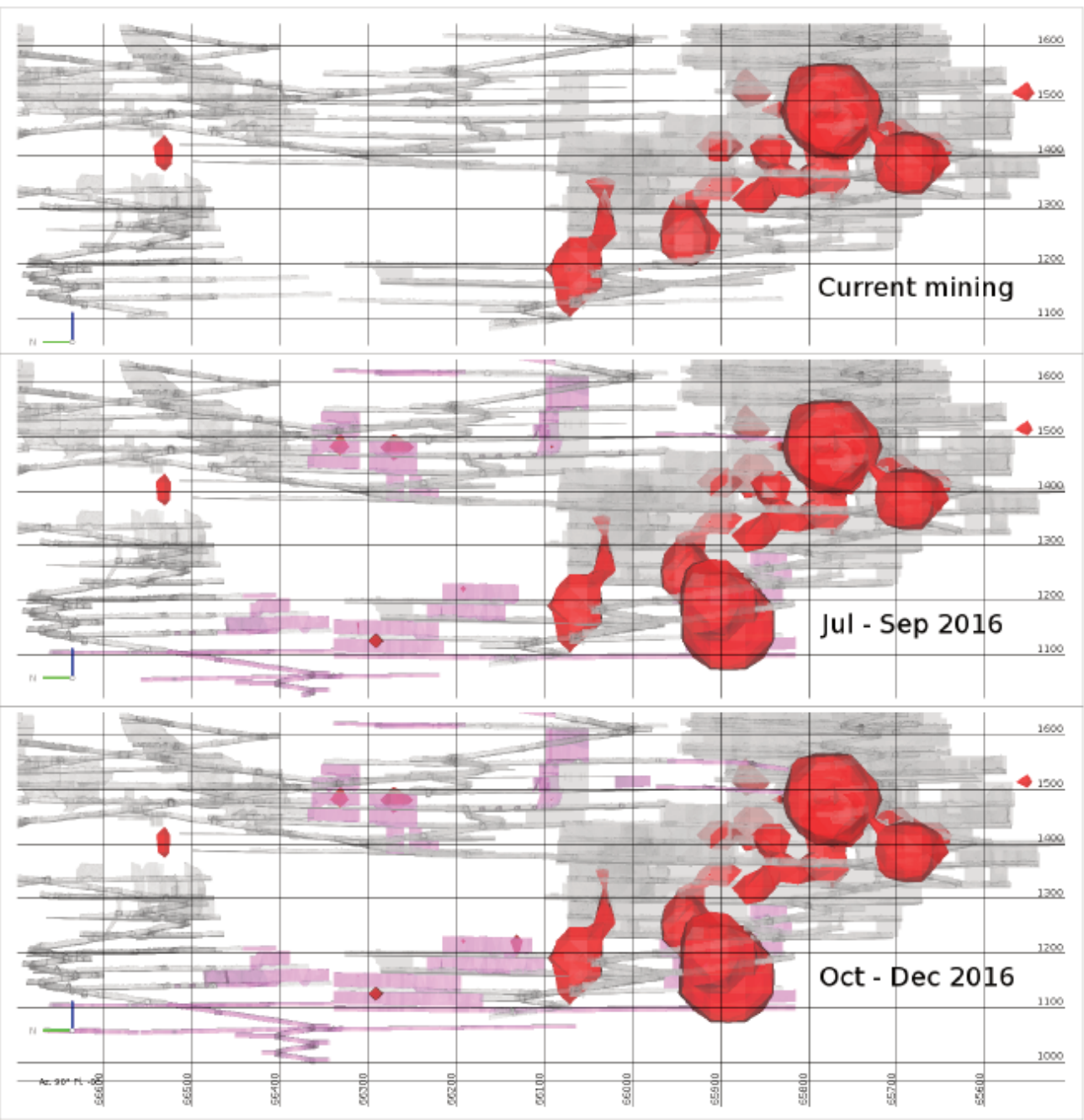

Figure 16 Evolution of seismic hazard for the planned mining sequence, with red wireframes representing isosurfaces for which the probability of occurrence of at least one event with $\log P \geqslant 0.1$ within $8,000 \mathrm{~m}^{3}$ in 92 days is 0.001 . The existing and planned future mining are displayed by grey and pink wireframes respectively (Malovichko 2017) 
Common to many of the aforementioned examples is that it is difficult to account for the release of energy from previous events on the same fault or geological structure. Moreover, not all available energy from a calculated seismic moment will be released in the form of seismic events. Hence, a quantitative agreement between modelled and recorded seismic moments should not be expected, and may not even be possible. Nevertheless, and similar to the case examples of caving simulation provided in this paper, even qualitative modelling is still very valuable in that it will enhance our understanding. It can be used for assessing the potential for mining-induced seismicity, but not model the event and the consequences dynamically. Using non-linear modelling, it is possible to account for failure both in the rock matrix, as well as along geological structures such as faults or deformation zones.

Whether an event is seismic or aseismic cannot be predicted with current knowledge and capabilities. To do so, the local mine stiffness and the post-peak behaviour of the rock mass must be possible to model in more detail than has been possible so far. We need better representation of the rock material and its behaviour in our models, and we need to improve on our characterisation of geological features. Key parameters are location, persistence, and topology of faults or deformation zones. A better characterisation requires joint efforts between seismologists, structural geologist, and rock mechanics engineers. Further development of probabilistic modelling approaches may be particularly attractive for prediction of seismic events since these are more likely to be statistically predictable rather than being possible to forecast in a deterministic fashion. Currently, a deterministic failure model used together with Monte Carlo simulations is often employed. This results in long computation times, which inhibits this from practical use for mine planning purposes.

\section{$3 \quad$ Vision for the future}

Some 10 years ago, I had the privilege to be involved in a project called 'Smart Mine of the Future', and more specifically the rock mechanics issues of this work. As part of this work, we described the state-of-the-art in numerical modelling, and outlined a vision for the future within the general framework of the study, with one important vision being to strive for zero accidents by development of technology. Obviously, one strategy for this is to have less (or no) personnel in production areas-a path that the industry is already following, with more remotely or automatically guided vehicles, intelligent communication systems, etc. However, such a vision does not eliminate geotechnical challenges since active production areas must still remain open and accessible. Also, the prospect of rehabilitating a severely damaged drift and re-establishing its ground support system remotely will in itself be a serious challenge. The demands on our ability to design ground support are thus increased, which in turn implies that we need better tools to describe the rock conditions, better knowledge of how the rock interacts with the reinforcement, better tools to design and analyse ground support, as well as to monitor the behaviour of the rock mass in both local- and mine-scale.

With respect to numerical modelling, the study focused on two general topics: (i) prediction of stresses and deformations (both static and dynamic) in underground mining, including the possible prediction of seismic events (temporally and spatially, including their magnitude); and (ii) real-time numerical modelling of the rock mass, i.e. obtaining calculation results in a very short time and continuously updating models used for such calculations.

As mentioned above, our ability to predict seismic events is still limited, at least with respect to temporal prediction. The potential for rock failure (intact rock failure and/or joint slip) can be assessed, including the possible seismic magnitudes resulting from such failures. However, whether a local failure results in a seismic event or not cannot be predicted with current knowledge and capabilities. Developments in this direction would need to include simulating the entire load-deformation curve of a rock material (i.e. including post-peak behaviour) and explicit fracturing of the material.

Real-time modelling has not yet been applied in rock mechanics, but there are examples of applications in other engineering and scientific disciplines, such as weather forecasting and physics modelling. The advances have primarily been driven by the increases in computing speed and capability over the last half century. The basic theories for weather forecasting were developed in the 1920s, and the advances since then are mainly in terms of resolution and speed of calculations. 
Based on this work, one may formulate a vision of future modelling in which the model is a mathematical copy of the rock mass, where the rock material is described in the small-scale utilising simple contact models, rather than elaborate constitutive material models. Such a model, in (near) grain-scale should then be possible to run for mine-scale analysis covering all scales of interest-from reinforcement and drift-scale to mine-scale (from a few centimetres to thousands of metres). Probabilistic modelling would be employed to account for remaining uncertainties in characterisation and to model phenomena that are not deterministic in nature, e.g. mining-induced seismicity. Finally, all of this is applied in a (near) real-time modelling fashion, with both static and dynamic calculations performed in the range of minutes.

Ten years down the road from when this was first formulated, this is still very much a vision; we have only taken small steps towards this possible goal. Both computational and post-processing times must be reduced by many orders of magnitudes. The outlined vision will also require improved input data compared to what is currently often the case. Although the last few years have seen a development of more extensive data sets being prepared as input, even the most extensive data sets still only sample a very small portion of the rock mass. Hence, there is clearly a need for more encompassing data collection and monitoring systems for future modelling improvements. An analogy may be made to the problem of mineral resource characterisation, in which different levels of confidence are used-inferred, indicated, and measuredeach one defined in terms of the amount and confidence of data required. The corresponding confidence levels for reserves are possible, probable, and proven. The same confidence levels could potentially be used for the geomechanical data characterisation at a site, and thus for classifying input data to modelling, but this is yet to be applied in practice.

An important aspect of all modelling is calibration and validation. One should also make use of all opportunities to calibrate models, i.e. adjusting input data (parameter values and/or material model) for a numerical model until the model output agrees with an observed behaviour. Good modelling examples are almost invariably well calibrated, but the fact that a model is calibrated for a certain case does not mean that it will behave correctly for another case. This is where the more stringent validation, i.e. determining the degree to which a model is an accurate representation of the real world from the perspective of the intended use(s), becomes important. One may argue that full validation of rock mechanical models may not be possible, given the complexities of the rock mass. But even a partial validation will be beneficial and increase the reliability of the model. An important aspect of this process is to define acceptance criteria for when a validation can be defined as 'successful', which may, in practice, differ depending on application, scale and objective of a particular model approach.

\section{$4 \quad$ Concluding remarks}

I would like to quote another passage from Starfield \& Cundall (1988):

"It is often tempting, once the modelling process is complete and a new understanding has been acquired, to point out that mechanisms are "obvious" and that the modelling was not really necessary. This is easy to say with hindsight: those who read detective novels also tend to say: "I knew who did it all along, "but only after they have finished the book!" (Starfield \& Cundall 1988)

In a recent lecture, Cundall (2020) further stated that:

"...there is an art to using the software tools correctly. It's not just a case of plugging in the data and hitting "run." We need to understand the underlying physics, and whether the model properly represents it." (Cundall 2020)

Both these quotes underline the importance of physics and mechanics, and that modelling is a great tool to increase our understanding. The most useful models are thus those that provide a good and reliable representation of the mechanisms. In some cases, this may be achieved through a very simple model, but in other cases, very advanced models may be required. The value of numerical models to mine planning and production is thus also linked to how well a model represents the important aspects for a specific case. While 
linear-elastic models may be perfectly fine in some cases, they may lead to severe misinterpretations in other cases, for example where there would be extensive plastic yield and deformation in a rock mass.

Ultimately, one could envision more integration of rock mechanical modelling with mine planning and production. Steps towards this are already being taken; e.g. the workflow outlined by Arndt et al. (2018). This workflow also involved aspects of machine learning. While this definitely will speed up post-processing and interpretation, there is an inherit risk that understanding may suffer with an increasing using of $\mathrm{Al}$ technology. Call me old fashioned, but I firmly believe that the human eye and mind should be our primary tools for interpretation and understanding. The current trend of less time spent underground and more time in front of computers is somewhat alarming. To also reduce time spent on looking at, and analysing, results would be a step in the wrong direction. We now have computers and tools that have greatly reduced menial tasks, such as preparing punch cards or manually meshing geometries-let's use this hard-won time by spending it on rock mechanics interpretation of results, and application to planning and production.

\section{Acknowledgement}

My career in rock mechanics started more than 30 years ago, initially being inspired by Professor Ove Stephansson at the Luleå University of Technology, and his colleagues, most notably Bengt Leijon, during my undergraduate and graduate studies. Both Bengt and Ove have passed away and are sorely missed by the community. My informal mentor over the years has been Mr Norbert Krauland, formerly head of rock mechanics at the Boliden Mineral mining company. I am forever grateful for his lifelong, never-ending enthusiasm and perseverance in the field of rock mechanics. I also acknowledge the support from my current colleagues within Itasca International Inc., who have contributed with ideas, material, and references for this paper, among others: Tryana Garca-Cruz, Catalina Álvarez, Yoann Hebert, Glenn Sharrock, Miguel Fuenzalida, Xin Wang, and Mikael Svartsjaern.

\section{References}

Álvarez, C, Gómez, P \& Nehgme, M 2014, 'Cratering prediction due to block caving', Proceedings of the ISRM Conference on Rock Mechanics for Natural Resources and Infrastructure, International Society for Rock Mechanics, Lisbon.

Andrieux, PP 2010, Numerical Modelling and High Stress Mining Situations, presentation at the Fifth Seminar on Deep and High Stress Mining, Santiago.

Arndt, S, Bui, T, Diering, T, Austen, I \& Hocking R 2018, 'Integrated simulation and optimisation tools for production scheduling using finite element analysis caving geomechanics simulation coupled with 3D cellular automata', in Y Potvin \& J Jakubec (eds), Proceedings of the Fourth International Symposium on Block and Sublevel Caving, Australian Centre for Geomechanics, Perth, pp. 247-260, https://doi.org/10.36487/ACG_rep/1815_16_Arndt

Beck, DA, Pfitzner, MJ, Arndt, SM \& Fillery, B 2009, 'Estimating rock mass properties and seismic response using higher order, discontinuous, finite element models', unpublished.

Beck, D, Levkovitch, V \& Simser, B 2012, 'Explicit discontinuum simulation for probabilistic forecasting of fault slip and rock mass seismic potential', in Y Potvin (ed.), Proceedings of the Sixth International Seminar on Deep and High Stress Mining, Australian Centre for Geomechanics, Perth, pp. 373-387, https://doi.org/10.36487/ACG_rep/1201_27_beck

Board, M 1996, 'Numerical examination of mining-induced seismicity', in G Barla (ed.), Proceedings of The ISRM International Symposium on Prediction and Performance in Rock Mechanics and Rock Engineering (Eurock 96), vol. 3, A.A. Balkema, Rotterdam, pp. 1469-1486.

Borg, T, Leijon, B, Röshoff, K \& Stephansson, O 1983, 'Bergmekanik för brytningsplanering på djupa nivåer i gruvan. Projekt Zinkgruvan, Slutrapport', Luleå University of Technology, Luleå (in Swedish).

Bouzeran, L, Furtney, J, Hazzard, J, Lemos, JV \& Pierce, M 2016, 'Advanced 3DEC bolt model for simulation of ground support performance in highly fractured and bulked rock masses', in E Nordlund, TH Jones \& A Eitzenberger (eds), Proceedings of the Eighth International Symposium on Ground Support in Mining and Underground Construction, Luleå University of Technology, Luleå, pp. 268-278.

Cancino, C, Álvarez, C, Gómez, P, Cavieres, P, Jara, R, Figueroa, C \& Millán, J 2020, 'Subsidence analysis of waste dumps located inside an active caving crater', in SAB da Fontoura, RJ Rocca \& J Pavón Mendoza (eds), Rock Mechanics for Natural Resources and Infrastructure Development, CRC Press, Boca Raton.

Cundall, PA 2020, The Art of Numerical Modeling in Geomechanics, presentation at the February 27 plenary of 68th University of Minnesota Geotechnical Conference, Minneapolis, https://www.youtube.com/watch?v=grVjOVnQwc0

Duplancic, P \& Brady BHG 1999, 'Characterisation of caving mechanisms by analysis of seismicity and rock stress', in G Vouille \& P Bérest (eds), Proceedings of the 9th ISRM Congress on Rock Mechanics, vol. 2, A.A. Balkema, Rotterdam, pp. 1149-1053.

Encyclopaedia Britannica 2020, viewed 11 September 2020, https://www.britannica.com/science/scientific-modeling 
Garza-Cruz, T \& Pierce, M 2018, Impact of Shear Stresses on Pillar Strength, presentation at the 2018 SME Annual Conference \& Expo, Minneapolis, 25-28 February 2018.

Garza-Cruz, T, Pierce, M \& Board, M 2019a, 'Effect of shear stresses on pillar stability: a back analysis of the Troy Mine experience to predict pillar performance at Montanore Mine', Rock Mechanics and Rock Engineering, vol. 52, pp. 4979-4996, https://doi.org/10.1007/s00603-019-02011-3

Garza-Cruz, T, Bouzeran, L, Pierce, M, Jalbout, A \& Ruest, M 2019b, 'Evaluation of ground support design at Eleonore Mine via bonded block modelling', in J Hadjigeorgiou \& M Hudyama (eds), Proceedings of the Ninth International Symposium on Ground Support in Mining and Underground Construction, Australian Centre for Geomechanics, Perth, pp. 341-356, https://doi.org/10.36487/ACG_rep/1925_23_Garza-Cruz

Hebert, Y \& Sharrock, G 2018, 'Three-dimensional simulation of cave initiation, propagation and surface subsidence using a coupled finite difference-cellular automata solution', in Y Potvin \& J Jakubec (eds), Proceedings of the Fourth International Symposium on Block and Sublevel Caving, Australian Centre for Geomechanics, Perth, pp. 151-166, https://doi.org/10.36487/ACG_rep/1815_09_Hebert

Herdocia, A 1991, Hanging Wall Stability of Sublevel Caving Mines in Sweden, PhD thesis, Luleå University of Technology, Luleå.

Hustrulid, W 1991, Hangingwall Stability, internal report, Luossavaara-Kiirunavaara Aktiebolag, Luleå.

Jalalifar, H \& Aziz, N 2012, 'Numerical simulation of fully grouted rock bolts', in M Andriychuk (ed), Numerical Simulation - From Theory to Industry, InTechOpen, London, https://doi.org/10.5772/48287

Jarufe Troncoso, J, Potvin, Y \& Wesseloo, J 2012, 'Application of the limit equilibrium strength to the seismic assessment of shear related seismicity', in Y Potvin (ed.), Proceedings of the Sixth International Seminar on Deep and High Stress Mining, Australian Centre for Geomechanics, Perth, pp. 389-400, https://doi.org/10.36487/ACG_rep/1201_28_juan

Jing, L 2003, 'A review of techniques, advances and outstanding issues in numerical modelling for rock mechanics and rock engineering', International Journal of Rock Mechanics and Mining Sciences, vol. 40, pp. 283-353.

Jing, L \& Hudson, JA 2002, 'Numerical methods in rock mechanics', International Journal of Rock Mechanics and Mining Sciences, vol. 39, pp. 409-427.

Karampinos E, Hadjigeorgiou, J \& Turcotte, P 2016, 'Discrete element modelling of the influence of reinforcement in squeezing conditions in a hard rock mine', Rock Mechanics and Rock Engineering, vol. 49, pp. 4869-4892.

Kvapil, R 1965, Pfeiler in Erzgruben, internal report, Boliden AB (in German).

Kvapil, R, Nordström, C \& Johansson, K 1967, 'Takets stabilitet och förstärkning i Zinkgruvan', Institutionen för Gruvbrytning, KTH, Stockholm (in Swedish).

Lupo, JF 1996, Evaluation of Deformations Resulting from Mass Mining of an Inclined Orebody, PhD thesis, Colorado School of Mines, Golden.

Malmgren, L 2005, Interaction Between Shotcrete and Rock - Experimental and Numerical Study, PhD thesis, Luleå University of Technology, Luleå.

Malovichko, DA 2017, 'Assessment and testing of seismic hazard for planned mining sequences', in J Wesseloo (ed.), Proceedings of the Eighth International Conference on Deep and High Stress Mining, Australian Centre for Geomechanics, Perth, pp. 61-77, https://doi.org/10.36487/ACG_rep/1704_02_Malovichko

Martin, CD \& Maybee, WG 2000, 'The strength of hard rock pillars', International Journal of Rock Mechanics and Mining Sciences, vol. 37, pp. 1239-1246.

Merriam-Webster 2020, viewed 11 September 2020, https://www.merriam-webster.com/dictionary/model

Pierce, M 2013, 'Numerical modeling of rock mass weakening, bulking and softening associated with cave mining', ARMA e-Newsletter Spring 2013, iss. 9.

Potvin, Y \& Hadjigeorgiou, J 2016, 'Selection of ground support for mining drives based on the Q-System', in E Nordlund, TH Jones \& A Eitzenberger (eds), Proceedings of the Eighth International Symposium on Ground Support in Mining and Underground Construction, Luleå University of Technology, Luleå.

Potvin, Y, Hadjigeorgiou, J \& Wesseloo, J 2019, 'Towards optimising ground support systems in underground mines', in J Hadjigeorgiou \& M Hudyama (eds), Proceedings of the Ninth International Symposium on Ground Support in Mining and Underground Construction, Australian Centre for Geomechanics, Perth, pp. 493-502, https://doi.org/10.36487/ACG_rep/1925_35_Potvin

Ryder, JA 1987, 'Excess shear stress (ESS): an engineering criterion for assessing unstable slip and associated rockburst hazards', Proceedings of the Sixth International Congress on Rock Mechanics, vol. 3, pp. 1211-1215, A.A. Balkema, Rotterdam.

Ryder, JA 1988, 'Excess shear stress in the assessment of geologically hazardous situations', Journal of the Southern African Institute of Mining and Metallurgy, vol. 88, no. 1, pp. 27-39.

Sainsbury, DP, Sainsbury, B-A \& Lorig, LJ 2010, 'Investigation of caving induced subsidence at the abandoned Grace Mine', in Y Potvin (ed.), Proceedings of the Second International Symposium on Block and Sublevel Caving, Australian Centre for Geomechanics, Perth, pp. 189-204.

Sainsbury, B-A, Sainsbury, DP \& Pierce, ME 2011a, 'Historical review of the development of numerical cave propagation simulations', in Sainsbury, Hart \& Nelson (eds), Proceedings Continuum and Distinct Element Numerical Modeling in Geomechanics, Itasca International Inc., Melbourne, pp. 23-36.

Sainsbury, DP, Sainsbury, B-A, Board, MP \& Lorig, L 2011b, 'Back-Analysis of Structurally Controlled Cave Initiation and Propagation at the Henderson Mine', in Proceedings ARMA 2011, 45th US Rock Mechanics/Geomechanics Symposium, San Francisco.

Sainsbury, B-A \& Stöckel, B-M 2012, 'Assessment of caving induced subsidence at the Kiirunavaara Lake orebody', Proceedings of the 6th International Conference and Exhibition on Mass Mining, Canadian Institute of Mining, Metallurgy and Petroleum, Montreal. 
Salamon, MDG, 1993, 'Some applications of geomechanical modelling in rockburst and related research', Proceedings of the 3rd International Symposium on Rockbursts and Seismicity in Mines, A.A. Balkema, Rotterdam, pp. 297-309.

Singh, UK, Stephansson, O \& Herdocia, A 1993, 'Simulation of progressive failure in hanging-wall and footwall for mining with sublevel caving', Transactions of the Institution of Mining Metallurgy, Section A: Mining Industry, vol. 102, pp. A188-A194.

Sjöberg, J 1992, Stability and Design of Stope Roofs and Sill Pillars in Cut-and-Fill and Open Stope Mining, licentiate thesis, Luleå University of Technology, Luleå.

Sjöberg, J, Perman, F, Quinteiro, C, Malmgren, L, Dahnér-Lindkvist, C \& Boskovic, M, 2012, 'Numerical analysis of alternative mining sequences to minimise potential for fault slip rockbursting', Mining Technology, vol. 121, no. 4, pp. 226-235.

Sjöberg, J, Perman, F, Lope Álvarez, D, Stöckel, B-M, Mäkitaavola, K, Storvall, E \& Lavoie, T 2017, 'Deep sublevel cave mining and surface influence', in J Wesseloo (ed.), Proceedings of the Eighth International Conference on Deep and High Stress Mining, Australian Centre for Geomechanics, Perth, pp. 357-372, https://doi.org/10.36487/ACG_rep/1704_25_Sjoberg

Stacey, TR 1981, 'A simple extension strain criterion for fracture of brittle rocks', International Journal of Rock Mechanics and Mining Sciences \& Geomechanics Abstracts, vol. 18, pp. 469-474.

Starfield, AM \& Cundall, PA, 1988, 'Towards a methodology for rock mechanics modelling', International Journal of Rock Mechanics and Mining Sciences \& Geomechanics Abstracts, vol. 25, pp. 99-106.

Stephansson, O, Borg, T \& Bäckblom, G, 1978, Sprickbildning i norra Kiirunavaaras hängvägg (Crack formation in the northern wall of Kiirunavaara), Technical Report 1978:51T, Luleå University of Technology, Luleå (in Swedish).

Svartsjaern, M, Hortberg, S, Sjöberg, J, Stöckel, B-M \& Mäkitaavola, K 2020 'Uppblockning, markdeformationer och inverkan av strukturer vid skivrasbrytning', Proceedings of Bergmekanikdagen 2020, Svenska Bergteknikföreningen, Stockholm, http://www.svbergteknik.se/UserFiles/Dokument/Bergdagarna_2020/BM_6_M_Svartsjaern_Uppblockning_markdeformati oner.pdf (in Swedish).

Vatcher, J, Boskovic, M \& Sjoberg, J 2019, 'Production-associated risk factors of seismicity in the Kiirunavaara mine', in J Wesseloo (ed.), Proceedings of the First International Conference on Mining Geomechanical Risk, Australian Centre for Geomechanics, Perth, pp. 261-272, https://doi.org/10.36487/ACG_rep/1905_14_Vatcher

Villegas, TF 2008, 'Numerical analyses of the hangingwall at the Kiirunavaara Mine', licentiate thesis, Luleå University of Technology, Luleå.

Villegas, TF \& Nordlund, E 2008, 'Numerical analyses of the hangingwall failure at the Kiirunavaara mine', Proceedings of the 5th International Conference and Exhibition on Mass Mining (MassMin 2008), Luleå University of Technology, Luleå, pp. 729-838.

Wang, X \& Cai, M 2017, 'Numerical analysis of ground motion in a South African mine using SPECFEM3D', in M Hudyma \& Y Potvin (eds), Proceedings of the First International Conference on Underground Mining Technology, Australian Centre for Geomechanics, Perth, pp. 255-268, https://doi.org/10.36487/ACG_rep/1710_20_Wang

Wilson, JW \& More-O'Ferrall, RC 1970, 'Application of the electric resistance analogue to mining operations', Journal of the Southern African Institute of Mining and Metallurgy, vol. 70, pp. 369-378. 